\title{
Cervical Vertebral Erosions and Subluxations in Rheumatoid Arthritis and Ankylosing Spondylitis
}

By William Martel and Jesse W. Page

Atlanto-axial and lower cervical subluxations are frequently present in rhematoid arthritis and ankylosing spondylitis. Vertebral erosions, particularly of the odontoid process, can often be demonstrated. Rheumatoid involvement of the occipito-atlanto-axial joints may cause a vertical translation of the cervical spine with respect to the skull; at times, this is associated with true basilar invagination.
Subluxation atlanto-axial e infero-cervical es frequentemente presente in arthritis rheumatoide $e$ in spondylitis ankylosante. Erosion vertebral, particularmente in le processo odontoide, es frequentemente demonstrabile. Le affection rheumatoide del articulationes occipitoatlanto-axial pote causar un translation del spina cervical con respecto al cranio. A vices isto es associate con ver invagination basilar.

$I^{T}$

T IS WELL KNOWN that the cervical spine may be affected in ankylosing spondylitis and juvenile rheumatoid arthritis, but this region has received little attention as a focus of rheumatoid artiritis in adults. Atlanto-axial subluxation has been reported in both rheumatoid arthritis and ankylosing spondylitis, ${ }^{1-3}$ but its significance and prevalence have not been sufficiently emphasized. This potentially dangerous complication is frequently undiagnosed. At times, it was the initial manifestation of rheumatoid disease ${ }^{+.5}$ and, occasionally, its relationship to coexisting arthritis was apparently not recognized. ${ }^{6,7}$

In this study, lateral roentgenograms in flexion and extension and laminagrams were made of the cervical spine in patients with rheumatoid arthritis or ankylosing spondylitis. These patients were selected because of persistent neck pain or the severity of their disease. Fifteen of 25 patients thus examined proved to have cervical subluxations, most often of the atlanto-axial joints. Vertebral erosions, particularly of the odontoid process, were observed in 14 patients. In 7 instances there was vertical displacement of the cervical spine relative to the skull, and in three of these, it was associated with invagination of the foramen magnum (basilar invagination).

\section{AnATOMY}

The odontoid process forms synovial joints anteriorly with the atlas and, posteriorly, with the transverse ligament (Fig. 1). The latter is a stout band on which the stability of the atlanto-odontoid joint depends. It arises from the

From the Departments of Radiology and Internal Medicine and the Rackham Arthritis Research Unit, The University of Michigan, Ann Arbor, Michigan.

The Rackham Arthritis Research Unit is supported by a grant from the Horace $H$. Rackham School of Graduate Studies, The University of Michigan. This project was also supported in part by a grant from the United States Public Health Service-Graduate Training Grant 2A 5025. 


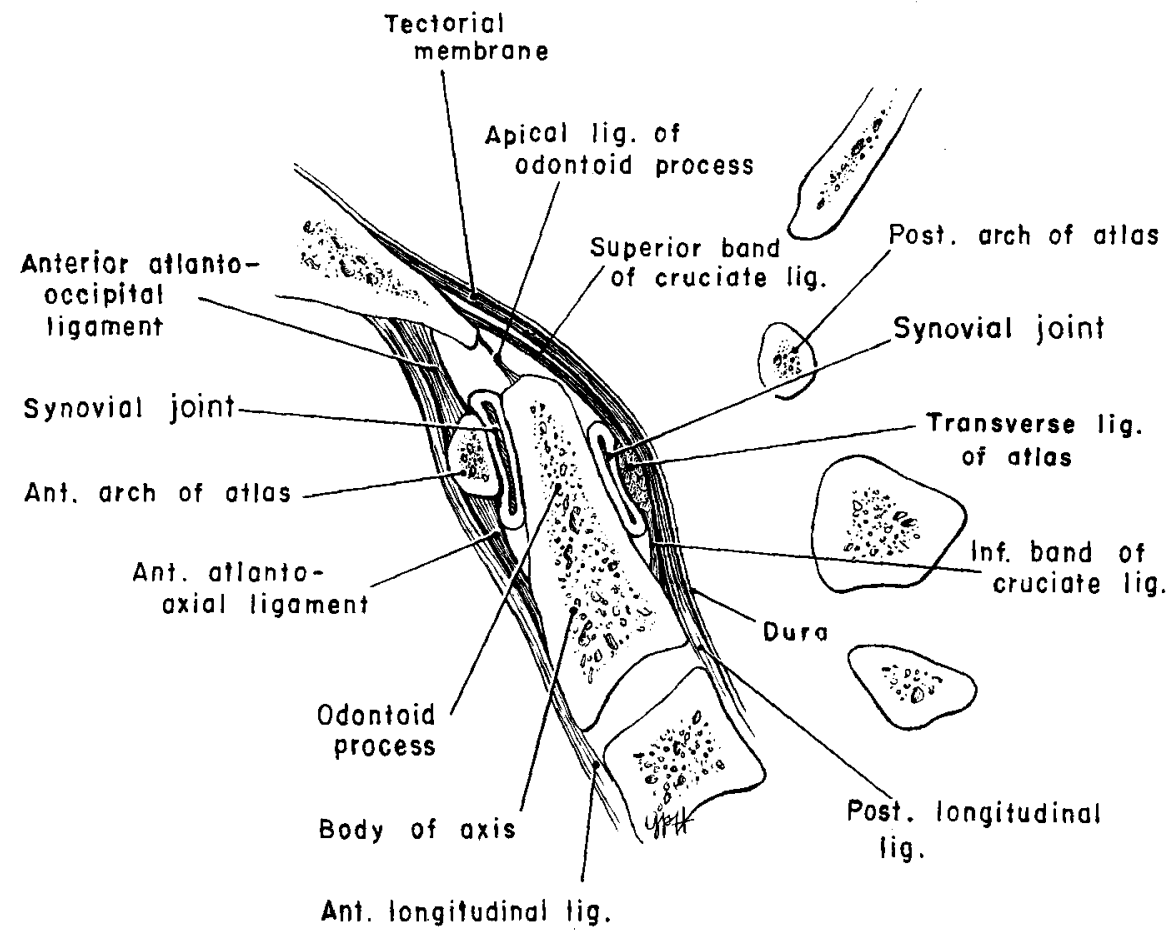

Fig. 1-Schematic drawing, midsagittal section of the upper cervical spine and foramen magnum, showing the relationship of the synovial tissue, ligaments, odontoid process and anterior arch of the atlas.

lateral masses and passes behind the odontoid, keeping it closely applied to the anterior arch of the atlas. A synovial bursa may be found at the posterior aspect of the transverse ligament ${ }^{\mathrm{s}}$ and, sometimes, between the dens and anterior margin of the foramen magnum., ${ }^{5,9}$ The proximity of synovial tissue to the odontoid process and ligaments vital to the stability of the upper cervical spine is of prime importance in explaining the lesions to be described below.

On lateral radiographs of the adult cervical spine the atlanto-odontoid distance, for practical purposes, is constant in flexion and extension and does not exceed $2.5 \mathrm{~mm} \cdot{ }^{10} \mathrm{~A}$ critical relationship also exists between the foramen magnum and cervical spine. Basilar invagination refers to an upward bulging of the margins of the foraman magnum, associated with vertical displacement of the spine. If the tip of the odontoid lies $4.5 \mathrm{~mm}$. above a line from the posterior margin of the hard palate to the most caudal point of the occipital curve (Fig. 2), pathology must be seriously considered. ${ }^{11}$ A second indication of basilar invagination is when the angle subtended by the clivus and the plane of the foramen magnum exceeds $136^{\circ} .{ }^{11-13}$

\section{Case Reports}

Case 1. (R. K. \#A2935)*: This 60 year old white male, who had rheumatoid arthritis for 22 years, developed progressive neck pain and severe weakness for which he was

"From the Veterans Administration Hospital, Ann Arbor, Michigan. (Presented at the annual meeting of the American Rheumatism Association, June 9-11, 1960.) 


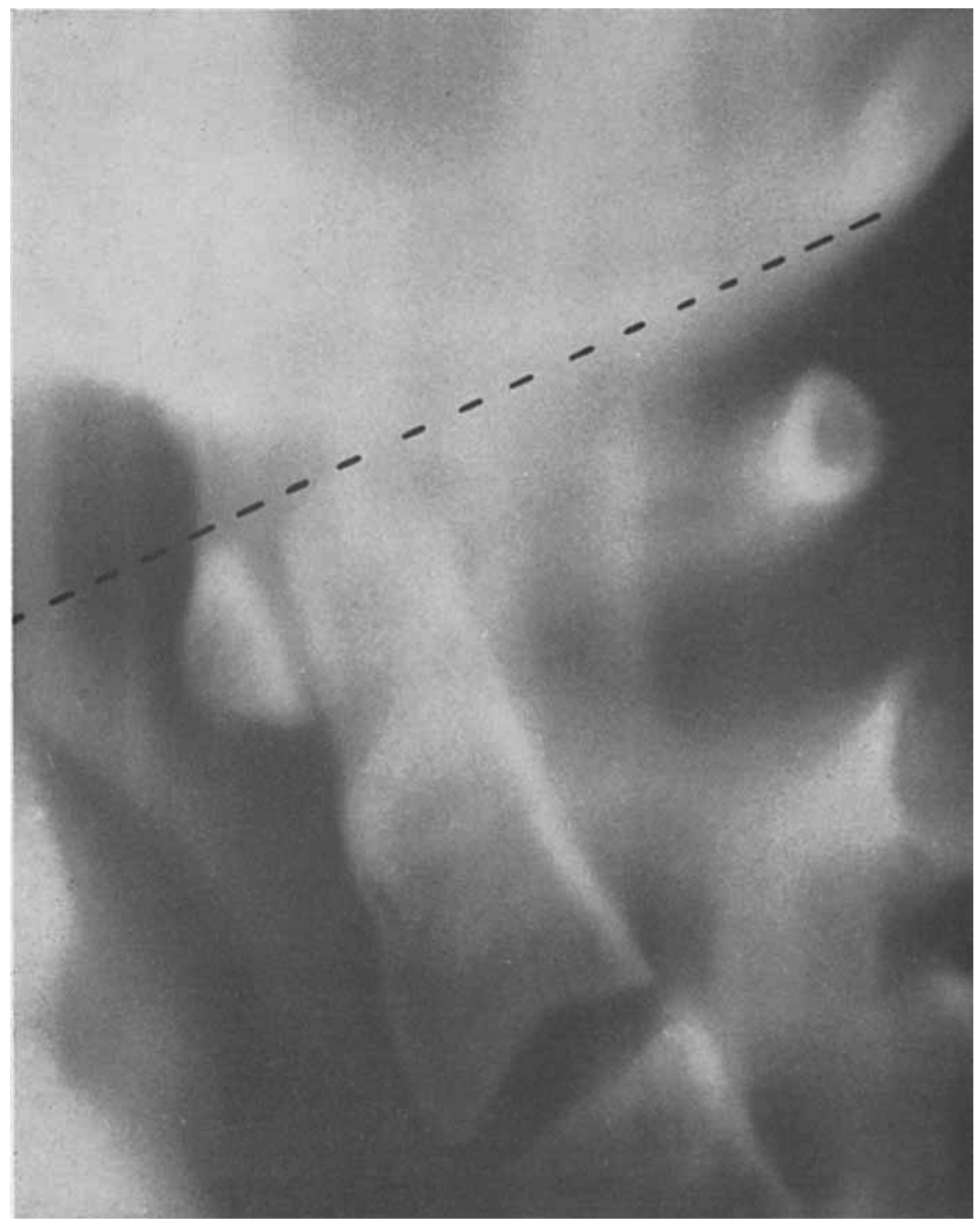

Fig. 2.-Midline laminagram of a normal upper cervical spine. Note the palatooccipital base line (dotted) and the sharp, smooth contour of the odontoid process with its rounded apex.

hospitalized in 1959. Adrenocortical steroids had been administered for several months during the preceding year. Physical examination showed generalized lymphadenopathy, marked limitation of neck motion and tenderness of the sternocleidomastoid muscles. There was a tender, subcutaneous nodule in the occiput. Active synovitis was present in multiple peripheral joints; his disease classification was Stage III progression, Class III function. ${ }^{14}$ Neurologic examination was normal except for muscular weakness. The Wintrobe sedimentation rate (corrected) was $34 \mathrm{~mm} . / \mathrm{hr}$. The latex fixation test for the rheumatoid factor was positive, $(1: 5120)$. + Radiographs of the hands and wrists showed typical

$\nmid$ Highest dilution tested. 


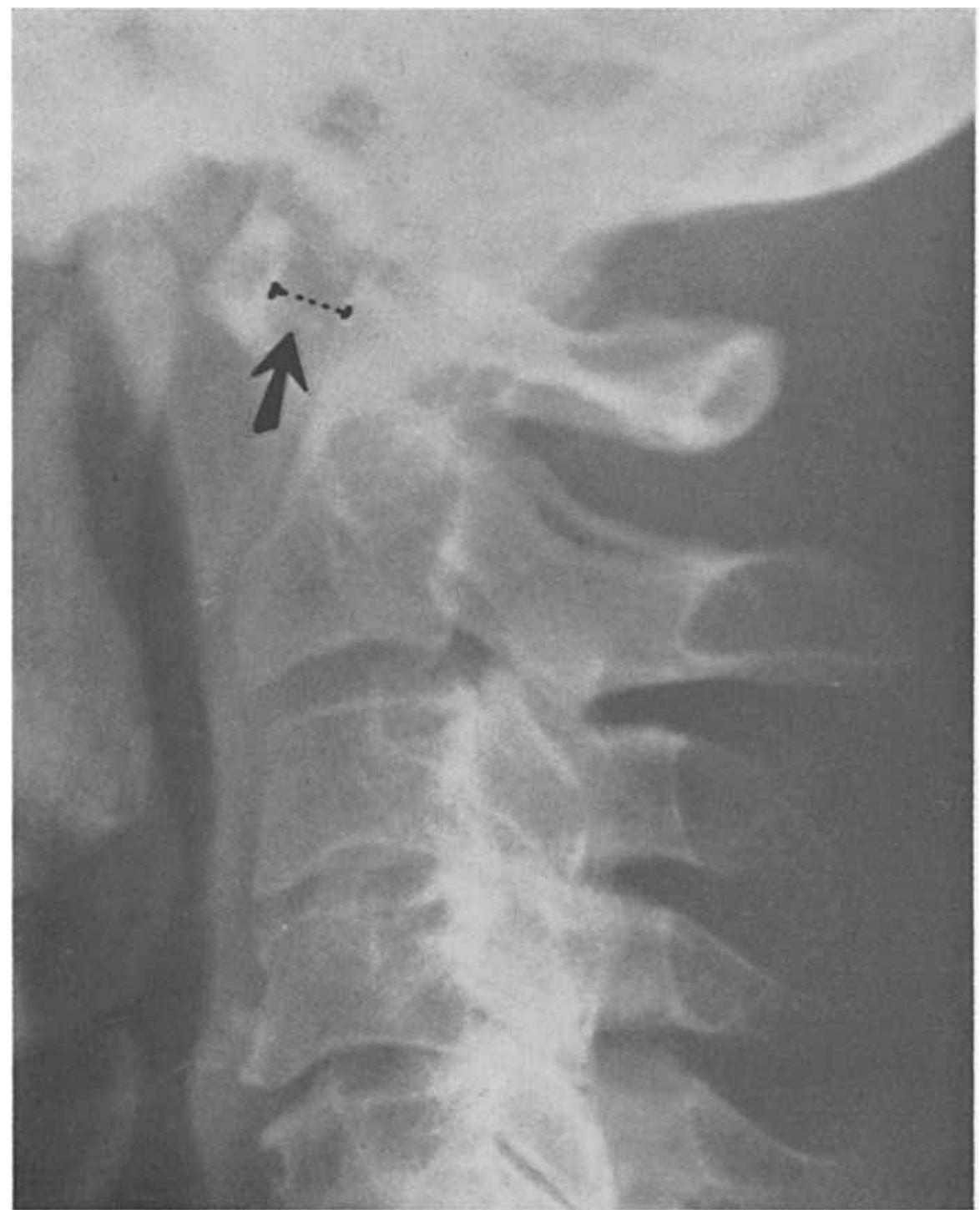

Fig. 3.-Case 1. Cervical spine, lateral view with flexion. The atlanto-odontoid distance (arrow) is abnormally wide, indicating an anterior subluxation of the atlas.

changes of rheumatoid arthritis. There was an anterior subluxation of the atlas in flexion with an atlanto-odontoid distance of $6 \mathrm{~mm} . \neq$ (Fig. 3).

While in the hospital he developed a left hemiplegia and expired. Cerebral arteriography had shown occlusion of the right internal carotid artery. At necropsy the atlantoaxial subluxation was confirmed and bilateral cerebral infarcts were demonstrated. Micro-

$\ddagger$ Measurements given in these case reports have been corrected for radiographic enlargement. The correction factor varies (83-87 per cent) depending on the distance of the spine to the film. The target film distance was 60 inches. An average correction factor of 85 per cent was used. 


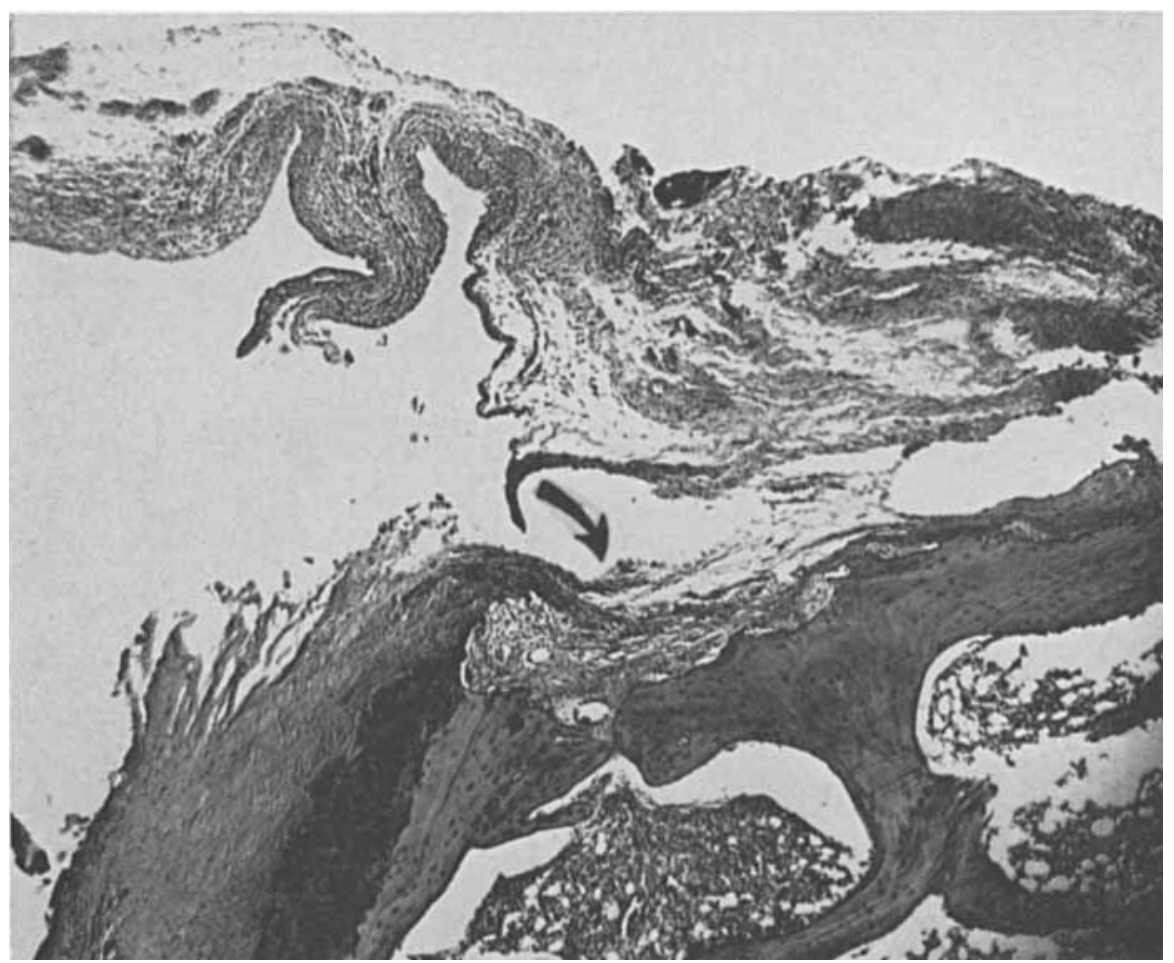

Fig. 4.-Case 1. Odontoid process, $\times$ 40. Chronic, non-specific synovitis (upper) and an osseous erosion (arrow) with ingrowth of proliferating pannus.

scopic examination of the odontoid process showed erosions of its cartilage and cortex, associated with ingrowth of proliferating pannus and an adjacent, chronic non-specific synovitis, (Fig. 4). Ligaments adjacent to the odontoid showed areas of fibrinoid necrosis with chronic inflammation.

Case 2. (G. M. \#643439) : In 1958, this 54 year old white male who had rheumatoid arthritis since 1942, complained of paresthesias and progressive weakness of the upper extremities, intermittent episodes of blurred vision and a staggering gait. He had noted shortening of his neck and crepitus over the cervical spine. Adrenocortical steroids had been taken for eight years. Physical examination showed widespread peripheral arthritis with multiple, subcutaneous rheumatoid nodules. There were bilateral extensor digitorum communis tendon ruptures. Neck motion was limited. There was muscular weakness of the upper extremities but no sensory impairment. The left biceps, triceps, patellar and Achilles reflexes were absent. There were no pyramidal tract signs. The Wintrobe sedimentation rate (corrected) was $35 \mathrm{~mm}$./ hr. The latex fixation test was positive, (1:5120). Roentgenograms of the cervical spine showed multiple subluxations, (Fig. 5 left). The atlanto-odontoid distance measured $15 \mathrm{~mm}$. The odontoid was abnormally small; its apex was pointed and a spicule of bone projected from its posterior aspect, (Fig. 5 right). The A-P diameter of the spinal canal at the level of the dens was $12 \mathrm{~mm}$. The atlanto-axial dislocation was reduced and the upper cervical spine was fused. It was noted that the ligamentum flavum between $\mathrm{C}_{1}$ and $\mathrm{C}_{2}$ was absent and the dura filled this space.

He developed severe pain in the upper dorsal spine 18 months later. At this time a

"Previously reported ${ }^{15,16}$ 


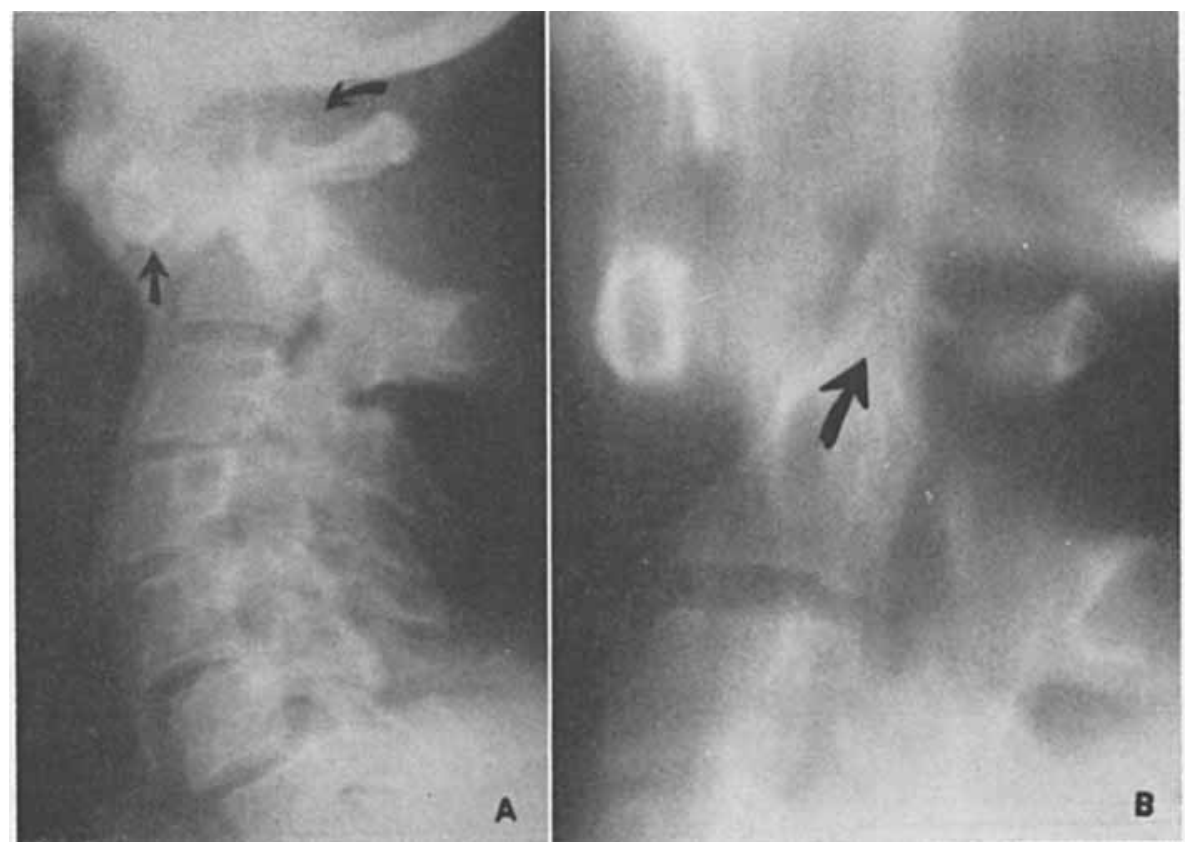

Fig. 5.-Case 2. (Left) Cervical spine, lateral view. Multiple cervical subluxations, especially at the atlanto-axial joint. The upper arrow points to the tip of the odontoid process and the lower one to the anterior arch of the atlas. (Right) Lateral midline laminagram. The odontoid process (arrow) is small and eroded. A spicule of bone projects from its posterior aspect.

dorsal kyphoscoliosis and tenderness over $\mathrm{D}_{4}$ and $\mathrm{D}_{5}$ were noted. Neurologic examination was negative except for absence of the Achilles reflex bilaterally. His arthritis was classified as Stage IV, Class IV. Roentgen films showed erosions of the intervertebral and anterior margins of $\mathrm{D}_{3}, \mathrm{D}_{4}$ and $\mathrm{D}_{3}$ with partial vertebral collapse and subluxation. The sacroiliac joints and lumbar spine were normal. The brucella agglutination and tuberculin skin tests were negative. Cultures of urine, sputum and gastric washings were negative for acid-fast bacilli.

Case 3. (D. S. \#756575): This 54 year old white male had severe rheumatoid arthritis since 1948 for which he had been treated with adrenocortical steroids for eight years. In 1959 he developed persistent, severe neck pain and occipital headaches which were aggravated by flexion of the head and relieved by lying down. On physical examination, neck motion was limited and there was tenderness over $\mathrm{C}_{3}$. Neurologic examination was negative. He had numerous subcutaneous rheumatoid nodules and multiple extensor digitorum communis tendon ruptures. His disease was classified as Stage IV; Class III. The Wintrobe sedimentation rate (corrected) was $31 \mathrm{~mm} . / \mathrm{hr}$. and the latex fixation test was positive, (1:5120). Roentgenograms showed normal cervical vertebral alignment with the head in neutral position (Fig. 6 left) but in flexion there was an anterior dislocation of the atlas, with an atlanto-odontoid distance of $10 \mathrm{~mm}$. Severe erosion of the odontoid process was demonstrated on laminagraphy. (Fig. 6 right). Erosions were also shown at the intervertebral surfaces of the body of $\mathrm{C}_{6}$. The sacroiliac joint margins were slightly irregular but sharply demarcated, without subchondral sclerosis.

Case 4. (B. W. \#626663): This 54 year old white female had progressive, severe rheumatoid arthritis since 1941, and was treated with adrenocortical steroids for seven years. She has had neck discomfort for eight years. Physical examination showed neck motion 


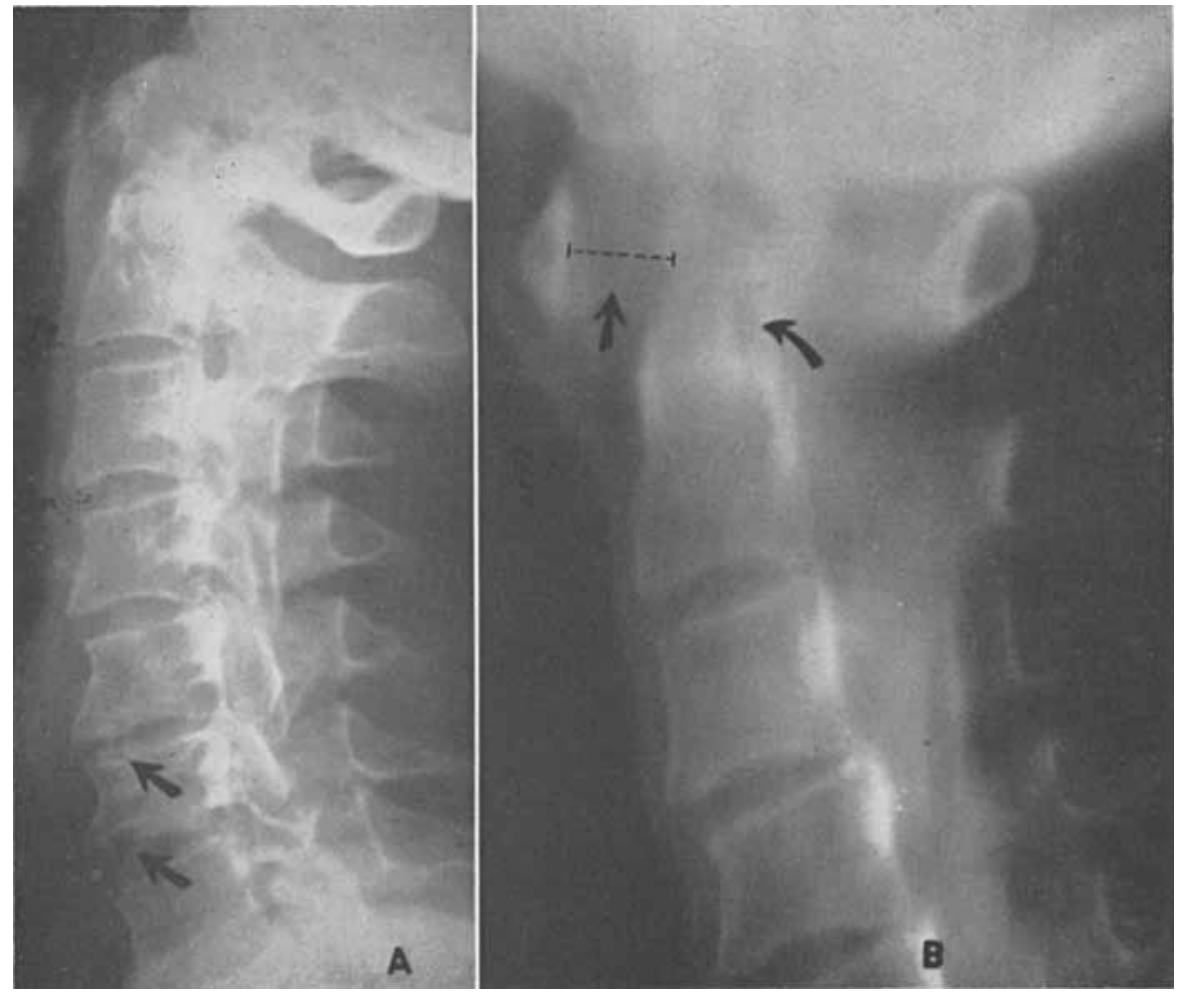

Fig. 6.-Case 3. Cervical spine, lateral view. (Left) Neutral position. Atlanto-axial subluxation is not evident. Minimal erosions are present at the margins of $\mathrm{C}_{6}$ (arrows). (Right) Lateral laminagram with flexion. The atlanto-odontoid distance (arrow) is clearly shown, as is the odontoid erosion (curved arrow).

to be painful and limited, with tenderness over the cervical spine. Neurologic examination was negative. She had severe deformity and active synovitis in most peripheral joints and multiple subcutaneous nodules were present. Her disease classification was Stage III, Class III. The Wintrobe sedimentation rate (corrected) was $30 \mathrm{~mm}$./hr. and the latex fixation test was positive, (1:5120). Roentgen films of the cervical spine showed generalized demineralization but no subluxation. Laminagrams disclosed multiple odontoid erosions. The sacroiliac joints and lumbar spine were normal.

Case 5. (G. $M$. \#7655-45): This white female developed rheumatoid arthritis at the age of 38 in 1941. Adrenocortical steroid therapy was given from 1951 to 1955 . Occipital and frontal headaches began in June 1952. She had a neck injury in August 1952 following which she did not have cervical pain or neurologic symptoms although she was told, at that time, that $x$-ray films disclosed a cervical dislocation. On physical examination in 1955 she had cervical lymphadenopathy, hepatomegaly and splenomegaly. Neck motion was limited but there were no neurologic abnormalities. There was active synovitis and advanced deformities of virtually all her peripheral joints with multiple, subcutaneous rheumatoid nodules. Her disease classification was Stage IV, Class III. The Wintrobe sedimentation rate (corrected) was $40 \mathrm{~mm}$./hr. and the sensitized sheep cell test (Ziff) was positive, $1: 448$ ). Roentgen films disclosed multiple cervical subluxations. The anterior arch of the atlas and the odontoid were $10 \mathrm{~mm}$. above the palato-occipital line and the foramen magnum-clivus angle was 140 degrees. The odontoid process was small and eroded as were the spinous processes of $C_{6}$ and $C_{7}$. The sacroiliac joint margins were 


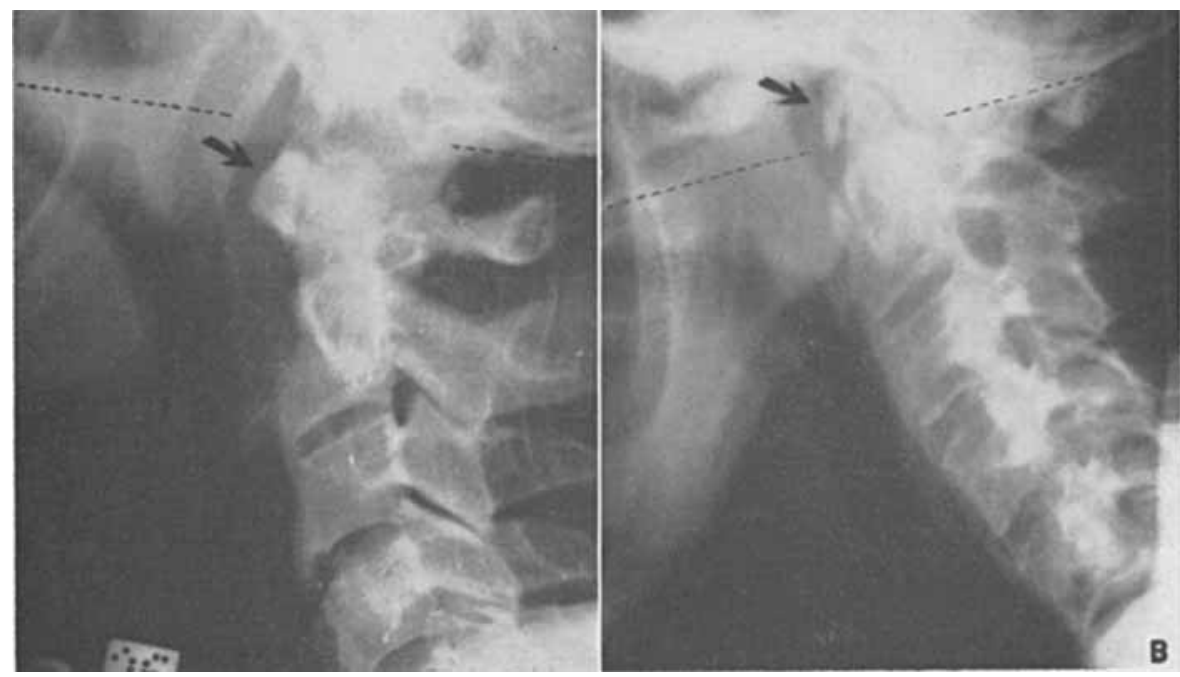

Fig. 7.-Case 6. Cervical spine, lateral view. (Left) 1951. The atlas (arrow) and odontoid are normal and lie beneath the anterior margin of the foramen magnum.

Note ossification along anterior ligament. (Right) 1959. The atlas and odontoid are above the palato-occipital line and anterior to the foramen magnum; these structures are now smaller and the atlas is probably fused to the occipital bone. Note the demineralization and blurred posterior facets.

eroded but sharply outlined, without subchondral sclerosis. There was no squaring of the lumbar vertebrae but the ischial tuberosities were eroded.

Case 6. (E. S. \#713526): This white male developed back pain and psoriasis in 1948, at the age of 34 . He developed severe limitation of back motion, extensive psoriasis and arthritis of virtually all peripheral joints. He received adrenocortical steroids between 1951 and 1959. He was admitted to the hospital in November 1959 because of persistent fever and a left pleural effusion. Physical examination disclosed almost total rigidity of the spine and severe limitation of chest expansion. The peripheral joints were markedly deformed and many showed complete ankylosis. There were no subcutaneous nodules. His classification was Stage IV, Class IV. Neurologic examination was difficult because of the skin disease and joint deformities. The latex fixation test for the rheumatoid factor was repeatedly negative. Roentgenograms showed that the anterior arch of the atlas was reduced in thickness and the odontoid had become small and pointed, (Fig. 7). These structures were not only above the palato-occipital base line but were considerably anterior to the foramen magnum, indicating that an atlanto-occipital subluxation had occurred. The atlas abutted against the base of the skull suggesting that a spontaneous atlanto-occipital fusion had apparently followed. There was bony ankylosis of the sacroiliac and virtually all of the vertebral apophyseal joints. Ossification along the paravertebral ligaments was extensive. His body temperature returned to normal with antibiotic therapy but the pleural effusion became loculated, and fever subsequently recurred. He expired and blood cultures, drawn a few hours before death, showed Alcaligenes and E. coli.

\section{Discussion}

Cervical subluxation, especially of the atlanto-axial joints, is more prevalent in rheumatoid disease than is recognized. Films in flexion are usually necessary for its demonstration. In some cases the abnormal increase in the atlantoodontoid distance is minimal and might be attributed to laxity rather than 
rupture of the transverse ligament. Such instability may also be due to erosion, with reduction in size, of the odontoid process for in such instances the odontoid fits, with room to spare, in the ring formed by the transverse ligament and anterior atlas. According to $W_{e r n e}^{5}$ the length of the alar ligaments limits the extent of forward dislocation of the atlas when the transverse ligament is ruptured.

Destructive vertebral lesions in rheumatoid arthritis ${ }^{17,18}$ may occur at the intervertebral margins near the disc, simulating tuberculous spondylitis. (Cases 2 and 3). Superficial erosions of the anterior margins of the vertebral bodies and of the spinous processes may be observed in ankylosing spondylitis, often giving the appearance of "wearing down of the bone." In this study, erosions of the odontoid cortex were demonstrable radiologically both in rheumatoid arthritis and ankylosing spondylitis. In the latter, they tended to be superficial and were sometimes associated with a sclerosing osteitis analogous to that which may be seen in the anterior corners of the vertebral bodies, the so-called "shining corners." 19 Laminagraphy was utilized to advantage to show the odontoid lesions more clearly and to delineate the precise relationship of the odontoid to the atlas. This technic need not be used routinely in clinical practice for conventional films will often show these structures with sufficient clarity. In doubtful cases, a midline laminagram will prove helpful.

Upward displacement of the spine relative to the skull may be caused by rheumatoid involvement of the occipito-atlanto-axial joints, (Case 6). Margulies, et al. ${ }^{20}$ described atlanto-occipital fusion in a patient with ankylosing spondylitis in whom atlanto-axial subluxation also occurred. In some of our cases, there was true basilar invagination as well. Decalcification, secondary to local chronic hyperemia, might allow the softened occipital condyles to be invaginated by the upward thrust of the atlas. Titrud, et al. ${ }^{21}$ reported a case of non-traumatic, atlanto-axial dislocation in which bone from $C_{1}$ and $C_{\text {: }}$ appeared soft but was not inflamed. They believed that regional hyperemia, secondary to an infection in the neck, caused vertebral decalcification. ${ }^{22}$ Rheumatoid erosion and destruction of the basilar process might also be postulated to explain the apparent, increased foramen magnum-clivus angle and would also account for severe cranial displacement of the spine with encroachment on the foramen magnum.

A perplexing observation in these patients was the lack of commensurate neurologic manifestations. The slow development of the cervical lesions, allowing an adaptation of the spinal cord, and the obligatory avoidance of head flexion might explain this discrepancy. Furthermore, the reduction in size of the odontoid, due to erosion, allows more room for the spinal cord than might otherwise be the case. However, we observed fatal spinal cord compression secondary to atlanto-axial subluxation in a patient with rheumatoid arthritis who died a few hours after iridectomy. In some instances, symptoms may be due to occlusion of the vertebral arteries; ${ }^{16,23}$ this factor may have been significant in Case 1. It is possible that, at least in some cases, significant neurologic manifestations are being overlooked.

The sacroiliac joints and lumbar spine were normal in most of the rheumatoid arthritis patients with cervical involvement. Occasionally, erosions of 
the sacroiliac joints were encountered in these, but they differed from the lesions in ankylosing spondylitis in that they were sharply demarcated, without subchondral sclerosis. Furthermore, none of these patients had paraspinal ossification or spinal ankylosis, but some had erosions of the ischial tuberosities and femoral trochanters. These cases frequently showed widespread rheumatoid nodule formation and strongly positive tests for the rheumatoid factor. None had significant limitation of motion in the lower spine. The occurrence of a "non-ankylosing spondylitis" in rheumatoid arthritis is to be emphasized. These cases are of interest for they not only lack the classic roentgen features of ankylosing spondylitis but differ clinically as well.

It should be recognized that in most of these patients the disease was progressive and prolonged. Almost all with rheumatoid arthritis had been treated with adrenocortical steroids; this may reflect the severity of the disease in these patients rather than a correlation with cervical subluxation. We have seen atlanto-axial subluxation and odontoid erosion in patients who did not have steroids. It remains to be determined whether prolonged steroid therapy, age of the patient, duration or severity of disease, or any other factor can be correlated with development of cervical spondylitis and subluxation in these patients.

\section{SUMmary}

Cervical subluxation, especially of the atlanto-axial joints, is frequent both in rheumatoid arthritis and ankylosing spondylitis. A lateral radiograph in flexion is often necessary for its demonstration. Erosions of the vertebral bodies and spines, and frequently of the odontoid process, occur in typical rheumatoid arthritis. Superficial erosions of the vertebral bodies, so called "anterior spondylitis," is well known in ankylosing spondylitis; similar lesions may involve the odontoid process in this disease and are sometimes associated with a sclerotic reaction analagous to the "shining corner" in the vertebral bodies. Vertical translation of the cervical spine may occur as a result of arthritis of the occipito-atlanto-axial joints and may be accompanied by basilar invagination. The slow development of these lesions, the destruction of the odontoid process and the avoidance of extreme flexion may explain in part the frequent absence of neurologic manifestations. The occurrence of spondylitis in typical rheumatoid arthritis is emphasized.

\section{ACKNOWLEDGMENTS}

It is a pleasure to express our appreciation for the helpful criticism and encouraging support of Drs. J. F. Holt and F. J. Hodges of the Department of Radiology and Drs. I. F. Duff, W. D. Robinson, and C. W. Castor of the Department of Internal Medicine.

\section{REFERENCES}

1. Purser, D. W. and Sharp, J.: Spontaneous atlanto-axial dislocation, a complication of spondylitis. J.Bone\& Joint Surg. 39B:582, 1957.

2. Kornblum, D., Clayton, M. L. and Nash, H. H.: Nontraumatic cervical dislocations in rheumatoid spondylitis. J.A.M.A. 149:431, 1952.
3. Voluter, G. and Werner, A.: Luxation atloido-axoidienne antérieure non traumatique chez l'adulte. J.radiol. et. Electrol. 37:176, 1956.

4. Pratt, T. L. C.: Spontaneous dislocation of the atlanto-axial articulation occurring in ankylosing spondylitis and rheumatoid arthritis. J.Fac.Ra- 
diologists. 10:40, 1959.

5. Werne, S.: Studies in spontaneous atlas dislocation. Acta orthop.Scandinav. Supp. 23:1, 1957.

6. Stammers, F. A. R. and Frazer, P.: Spontaneous dislocation of the atlas. Lancet 2:1203, 1933.

7. Rand, C. W.: The Neurosurgical Patient: His problems of Diagnosis and Care. Springfield, Ill., C. C. Thomas, 1944 , p. 47.

8. Cunningham's Textbook of Anatomy; Brash, J. C., Editor, ed. 9, London, Oxford Univ. Press, 1951.

9. Trolard: Les articulations de la tete avec lo collonne vertebrale. Etude sur quelques points de ces articulations. J. de Anatomie, 33:105, 1897.

10. Jackson, H.: The diagnosis of minimal atlanto-axial subluxation. Brit.J.Radiol. 23:672, 1950.

11. McGregor, M.: The significance of certain measurements of the skull in the diagnosis of basilar impression. Brit.J.Radiol. 21:171, 1948.

12. Boogard, J. A.: De indrukking der grandvlakte van den schedel door de vervelkolom, hare oorzaken en gevolgen. Neder.tijdschr. Geneesk. 2: 81, 1865.

13. McRae, D. L.: Bony abnormalities in the region of the foramen magnum. Correlation of the anatomy and neurologic findings. Acta radiol. 40: 335, 1953.

14. Steinbrocker, O., Traeger, C. H. and Batterman, R. C.: Therapeutic criteria in rheumatoid arthritis, J.A.M.A. 140:659, 1949.

15. Mikkelsen, W. M., Duff, I. F. and Robinson, W. D.: Unusual manifes- tations of rheumatoid nodules. J.Mich. M.Soc. 54:292, 1955.

16. Schneider, R. C. and Crosby, E. C.: Vascular insufficiency of brain stem and spinal cord in spinal trauma. Neurology 9:643, 1959 .

17. Baggenstoss, A. H., Bickel, W. H. and Ward, L. E.: Rheumatoid granulomatous nodules as destructive lesions of vertebrae. J.Bone \& Joint Surg. 34-A:601, 1952.

18. Gibson, H. J.: Ankylosing spondylitis. Aetiology and pathology. J.Fac.Radiologists. 8:193, 1957.

19. Romanus, R. and Yden, S.: Pelvospondylitis ossificans. Munksgaard, Copenhagen, 1955.

20. Margulies, M. E., Katz, I. and Rosenberg, M.: Spontaneous dislocation of the atlanto-axial joint in rheumatoid spondylitis. Recovery from quadriplegia following surgical decompression. Neurology 5:290, 1955.

21. Titrud, L. A., McKinlay, C. A., Camp, W. E. and Hannah, H. B.: Nontraumatic atlanto-axial dislocation. Report of a case with recovery after quadriplegia. J.Neurosurg. 6:174, 1949.

22. Cited by Titrud, et al. Greig, D. M.: Clinical Observations on the Surgical Pathology of Bone. Edinburgh, Oliver and Boyd, 1931, p. 227.

23. Ford, F. K.: Syncope, vertigo, and disturbances of vision resulting from intermittent obstruction of the vertebral arteries due to defect in the odontoid process and excessive mobility of the second cervical vertebra. Bull. Johns Hopkins Hosp. 91:168, 1952.

William Martel, M.D., Assistant Professor in Radiology, Department of Radiology, The University of Michigan, Ann Arbor, Michigan.

Jesse W. Page, M.D., Physician Trainee, Rackham Arthritis Research Unit, Horace H. Rackham School of Graduate Studies; Instructor, Department of Internal Medicine, The University of Michigan, Ann Arbor, Michigan. 